\title{
Microbial Profile and Antibiotic Resistance Pattern of Urine and Biofilm Pathogens Isolated from Catheterized Patients at Komfo Anokye Teaching Hospital, Kumasi, Ghana
}

\author{
Alexander Bekoe ${ }^{*}$, Roland Azorliade ${ }^{2}$, Anthony Ablordey ${ }^{3}$, Matthew Glover Addo ${ }^{1}$ \\ ${ }^{1}$ Department of Theoretical and Applied Biology, Kwame Nkrumah University of Science and Technology, Kumasi, Ghana \\ ${ }^{2}$ Department of Urology, Komfo Anokye Teaching Hospital, Kumasi, Ghana \\ ${ }^{3}$ Bacteriology Department, Noguchi Memory Institute for Medical Research, University of Ghana, Legon, Ghana \\ Email: *nanakbekoe@gmail.com
}

How to cite this paper: Bekoe, A., Azorliade, R., Ablordey, A. and Addo, M.G. (2021) Microbial Profile and Antibiotic Resistance Pattern of Urine and Biofilm Pathogens Isolated from Catheterized Patients at Komfo Anokye Teaching Hospital, Kumasi, Ghana. Journal of Biosciences and Medicines, 9, 1-13.

https://doi.org/10.4236/jbm.2021.910001

Received: August 9, 2021

Accepted: October 5, 2021

Published: October 8, 2021

Copyright $\odot 2021$ by author(s) and Scientific Research Publishing Inc. This work is licensed under the Creative Commons Attribution International License (CC BY 4.0).

http://creativecommons.org/licenses/by/4.0/ Open Access

\begin{abstract}
Introduction: Urinary tract infection represents more than $40 \%$ of all nosocomial infections of which $80 \%$ are attributed to the use of an indwelling urinary catheter. Although the device is useful medically to treat urinary retention and incontinence, its uses have also been associated with infections such as catheter-associated urinary tract infections. Objectives: To evaluate catheter-associated urinary tract infection in terms of its prevalence, pathogens causing the infection and the resistance pattern to some commonly used antibiotics. Methods: Urine and biofilm specimen were collected from $105 \mathrm{ca}-$ theterized patients. Bacteria pathogens were identified based on colony morphology, Gram staining and other biochemical reactions. Kirby-Bauer disc diffusion method was employed to determine the antibiotic resistance pattern of the isolated pathogens. Results: The study recorded a $74.29 \%$ prevalence of catheter-associated urinary tract infection among the rarely symptomatic patients. Escherichia coli were significantly isolated $(\mathrm{p}<0.000)$ in both samples compared to Klebsiella pneumoniae and Staphylococcus aureus. Most isolated pathogens from both samples were resistant to ciprofloxacin with the biofilm pathogens being highly resistant than the urine pathogens. K. pneumoniae from both samples showed higher resistance levels to antibiotics than $E$. coli and $S$. aureus. Conclusion: Ciprofloxacin, a commonly used antibiotic by catheterized patients turn out to be less effective against the pathogens. The use of ciprofloxacin in catheter-associated urinary tract infection treat-
\end{abstract}


ment should therefore be given a second thought.

\section{Keywords}

Asymptomatic, Biofilm, Catheterization, Retention, Uropathogen

\section{Introduction}

Globally, Urinary Tract Infection (UTI) is among the common bacterial infections in humans and can be acquired in the community and in hospital settings as a Health-care Acquired Infection (HAI) or nosocomial infection [1]. UTI represents more than $40 \%$ of all nosocomial infections of which $80 \%$ is attributed to the use of the indwelling urinary catheter [2]. Although indwelling urinary catheters are useful medical devices for the purposes of treating urinary retention and incontinence, their use has also been associated with infectious and non-infectious conditions such as catheter-associated urinary tract infection (CAUTI) and urethral strictures respectively [3].

CAUTI occurs as microorganisms that access the urinary bladder. This may happen as the tip of the catheter pushes colonized bacteria at the urethra into the bladder. Also, bacteria from a contaminated urinary bag can ascend through the tube into the bladder. These bacteria may use the catheter lumen as an entry or through the catheter-urethral interface [4]. Most of them are the host's own microflora or microflora from health personnel, other patients, or the environment. Bacteria usually encountered in CAUTI include Escherichia coli, Klebsiella pneumoniae, other Enterobactericeae and Staphylococcus species [5] [6] [7]. These bacteria use the device surface medium as a platform for biofilm formation immediately after catheterization in both the interior and exterior surface of the catheter through several steps [3] [8]. The biofilm formation is a strategic way for the bacteria to protect themselves against the host immune response and antibiotics in other to survive and cause more harm [9].

More than one million CAUTI cases are recorded each in the United States and the United Kingdom annually with about 13,000 and 25,000 mortalities respectively [10] [11]. In Africa, data on HAI including CAUTI is scanty with about $66 \%$ of countries with no recorded data [10]. However, with the few available data, CAUTI rates range from $23 \%$ to over $90 \%$ for short-term catheterization period to long-term catheterization period respectively [12] [13]. Available data suggest that only two studies have documented CAUTI rates in Ghana with high rates attributed to age, catheter duration and morbidity [14] [15]. Nevertheless, the incidence of CAUTI at Komfo Anokye Teaching Hospital (KATH) remains unknown. This study, therefore, seeks to evaluate CAUTI in terms of its prevalence, pathogens causing the infection and the resistance pattern to some commonly used antibiotics. This may be useful as a guide to empirical treatment and a basis to compare other studies. 


\section{Methods}

\subsection{Study Site}

The study was performed from June 2018 to March 2019 at the Urology Department under the surgical directorate of KATH. The hospital is a 1200 bed capacity facility situated at the Ashanti Regional capital, Kumasi, geographically located at the middle zone of Ghana with $6^{\circ} 40^{\prime} \mathrm{N}, 1^{\circ} 37^{\prime} \mathrm{W}$ coordinates. As the second-largest tertiary hospital in the country, it receives direct referrals from 12 out of the 16 administrative regions of the country. It also serves some parts of neighboring countries like Burkina Faso, Togo and Ivory Coast. This could be attributed to the road network of the country and the hospital's location.

\subsection{Study Design}

This cross-sectional study recruited 105 catheterized patients using a convenience-sampling method as patients came in to change their catheter. Interview-based questionnaires were administered to gather patient's biodata and other relevant information related to their catheterization.

Inclusive and exclusive criteria were considered in recruiting appropriate patients for the study. The inclusive criteria included oral or documented consent from patients. In cases of comatose and underage patients, consent was obtained from their relatives. Patients undergoing indwelling urethral catheterization for urinary retention or incontinence were recruited. Also, the catheter lumen of the patient must have developed visible biofilm. Patients must have been catheterized for not less than two calendar days. Patients must not be on antibiotics for at least the past two weeks. Patients to exclude were those undergoing antibiotic therapy, those with suggestive symptoms of urinary tract infections prior to their catheterization and patients who refuse to consent for the study.

\subsection{Specimen Collection}

About $5-10 \mathrm{ml}$ of urine was aseptically aspirated from the distal end of the catheter immediately after insertion of the device into the bladder. Each sample was labeled with the patient's identification number, date and time of sampling. Biofilm seen by the naked eye in the catheter lumen was collected aseptically by cross-sectional cut with a pair of sterile surgical scissors into a sterile zip-locked bag, also labeled with the patient's unique number and time of sampling. The collected samples were immediately put on ice and transported to the department's microbiological research laboratory for further analysis.

\subsection{Laboratory Analysis of Specimen}

\subsubsection{Urinalysis}

Urine test strips (ACON labs, USA) were used to analyze leukocytes and nitrite of the urine by immersing a dry reagent strip (dipsticks) into urine and allowing it to stand for about 10 seconds. The color change of the strip was compared with the standard chart and results were recorded. 


\subsubsection{Specimen Culture and Identification of Isolates}

Biofilms in the catheter were pre enriched with $15 \mathrm{ml}$ of maximum recovery diluent, pulsified for 2 minutes to extract biofilm from the catheter lumen into the diluent, and incubated at $37^{\circ} \mathrm{C}$ for 6 hours. Each sample (urine and biofilm) was aseptically inoculated on Mannitol Salt Agar (Oxoid, UK), Eosin Methyl Blue (Oxoid, UK) and Simmon Citrate Agar (Oxoid, UK) plus 1\% Myoinositol Salt and incubated at $37^{\circ} \mathrm{C}$ for $18-24$ hours.

Pure colony count of $10^{5} \mathrm{cfu} / \mathrm{ml}$ was recorded as significant bacteriuria for the urine whilst growth on the biofilm plates were all counted. Plates without growth for the 18 - 24 hours were incubated for another 24 hours. Single isolated colonies were picked and subcultured on nutrient agar to obtain pure cultures. The colony growth on the media was identified by their morphological appearance and standard biochemical tests such as Indole test, Citrate test, Catalase test, Coagulase test and Gram stain.

\subsection{Antibiotic Resistance Test}

An Antibiotic sensitivity test was performed for all the isolates using the Kirby-Bauer disc diffusion method on Muller Hinton Agar (MHA, Oxoid, UK) as recommended by the Clinical and Laboratory Standard Institution [16]. The following commonly used antibiotics: cefazolin $(30 \mathrm{mcg})$, ciprofloxacin $(5 \mathrm{mcg})$, nitrofurantoin $(300 \mathrm{mcg})$, fosfomycin $(50 \mathrm{mcg})$ and trimethoprim $(5 \mathrm{mcg})$ all from Oxoid, UK were used for the test. Zones of inhibition around the discs were measured and compared with the CLSI zone measurement chart for interpretation. K. pneumoniae ATCC 700603, E. coli ATCC 25922 and S. aureus ATCC 25923 strains were used for quality control.

\subsection{Data Analysis}

Statistical analysis was completed using Graph Pad Prism version 5. Study variables were computed for descriptive analysis such as arithmetic means, frequencies and percentages. Chi-square test was used to compare data across study parameters. A value of $\mathrm{P}<0.05$ was considered statistically significant.

\subsection{Ethical Approval}

Committee on Human Research, Publication and Ethics of the Kwame Nkrumah University of Science and Technology, Kumasi, Ghana approved the study (CHRPE/AP/144/18). Written informed consent was obtained from all study participants.

\section{Results}

\subsection{Demographic and Clinical Features of Study Subjects}

Out of one hundred and five participants recruited for the study, only one of them was a female representing $0.95 \%$. The age range of the study participants was 18 to 98 with an overall mean age of $61.6 \pm 17.28$. Table 1 shows the rest of their demographic features. 
Table 1. Demographic features of the study participants.

\begin{tabular}{|c|c|c|c|}
\hline & Demographics & Frequencies (n) & Percentage (\%) \\
\hline \multirow{2}{*}{ GENDER } & MALE & 104 & 99.05 \\
\hline & FEMALE & 1 & 0.95 \\
\hline \multirow{6}{*}{ AGE } & $0-17$ & 0 & \\
\hline & $18-35$ & 8 & 7.62 \\
\hline & $36-53$ & 10 & 9.52 \\
\hline & $54-71$ & 44 & 41.91 \\
\hline & $72-89$ & 37 & 35.24 \\
\hline & $>89$ & 6 & 5.71 \\
\hline \multirow{4}{*}{ RELIGION } & Muslim & 15 & 14.29 \\
\hline & Christian & 88 & 83.81 \\
\hline & Traditionalist & 1 & 0.95 \\
\hline & Other & 1 & 0.95 \\
\hline \multirow{4}{*}{ MARITAL STATUS } & Single & 10 & 9.25 \\
\hline & Divorce & 12 & 11.43 \\
\hline & Widow/Widower & 27 & 25.71 \\
\hline & Married & 56 & 53.33 \\
\hline
\end{tabular}

$\mathrm{n}=$ number of study participants, total number of study participants $=105$.

The reasons for catheterization were urinary retention (97.14\%) and urinary incontinence $(2.86 \%)$. As at the time of the study, the duration for patient catheterization was between 6 days to 12 years. The highest catheterized duration among the participants was between 1 to 12 months (30.48\%), 3 to 4 years (28.57\%), followed by 1 to 2 years $(24.76 \%)$ and those catheterized for more than 5 years $(11.43 \%)$. The most prevalent morbidity among the patients was prostate enlargement (90.49\%), urethral injury (4.76\%), loin fracture $(2.85 \%)$ and gonorrhea (1.90\%). Furthermore, about 60 of the participants had comorbidities such as hypertension (50.82), diabetes (27.87\%) followed by stroke (16.39\%) and Hernia (4.92\%). Various symptoms of UTI were exhibited by $42(40.00 \%)$ of the study participants as shown in Table 2 .

\subsection{Isolated Pathogens in Urine and Biofilm}

There was a $100 \%$ growth of microbes from the biofilm samples and about $97 \%$ growth from the urine samples. In all, 267 bacteria pathogens were isolated from both urine and biofilm samples. The biofilm recorded 147 pathogens whiles the urine recorded 120 isolated pathogens. The p-value recorded for $E$. coli versus $K$. pneumoniae isolated from the urine was (0.000) whiles the same isolates from the biofilm samples recorded $\mathrm{p}<0.001$. E. coli isolated from urine and biofilm samples were significantly higher $(\mathrm{p}<0.000)$ compared to $S$. aureus isolates from both. However, there were no significant differences among $K$. pneumoniae and 
Table 2. Clinical features of the study participants.

\begin{tabular}{|c|c|c|c|}
\hline \multicolumn{2}{|l|}{ Features } & \multirow{2}{*}{$\begin{array}{c}\text { Frequencies (n) } \\
102\end{array}$} & \multirow{2}{*}{$\begin{array}{c}\text { Percentage (\%) } \\
97.14\end{array}$} \\
\hline REASON FOR & Urinary Retention & & \\
\hline CATHETERIZATION & Urinary Incontinence & 3 & 2.86 \\
\hline \multirow{4}{*}{ MORBIDITY } & Gonorrhea & 2 & 1.90 \\
\hline & Loin fracture & 3 & 2.85 \\
\hline & Prostate & 95 & 90.49 \\
\hline & Urethral injury & 5 & 4.76 \\
\hline \multirow{4}{*}{ COMORDIDITY } & Diabetes & 17 & 27.87 \\
\hline & Hernia & 3 & 4.92 \\
\hline & Hypertension & 31 & 50.82 \\
\hline & Stroke & 10 & 16.39 \\
\hline \multirow{5}{*}{ SYMPTOMS } & Abdominal pain & 6 & 14.29 \\
\hline & Fever & 17 & 40.48 \\
\hline & Loin pain & 5 & 11.90 \\
\hline & Catheter blockage & 6 & 14.29 \\
\hline & Hematuria & 8 & 19.04 \\
\hline \multirow{2}{*}{ ANTIBIOTICS USAGE } & Yes & 41 & 39.05 \\
\hline & No & 64 & 60.95 \\
\hline \multirow{3}{*}{$\begin{array}{l}\text { ANTIBIOTICS LAST TAKEN } \\
\text { ( } 2 \text { weeks - } 2 \text { years })\end{array}$} & $<1$ Month & 18 & 43.90 \\
\hline & $1-12$ months & 20 & 48.78 \\
\hline & $>1$ Years & 3 & 7.32 \\
\hline \multirow{2}{*}{ PRESCRIBER } & Friend/Relative & 6 & 14.63 \\
\hline & Doctor & 31 & 75.61 \\
\hline \multirow{3}{*}{ URINALYSIS (dipstick) } & Others & 4 & 9.76 \\
\hline & Leukocyte & 98 & 93.33 \\
\hline & Nitrite & 91 & 86.67 \\
\hline
\end{tabular}

$\mathrm{n}=$ number of study participants, total number of study participants $=105$.

S. aureus isolates from both urine $(\mathrm{p}=0.219)$ and biofilm $(\mathrm{p}=0.311)$ samples. Figure 1 shows the occurrence of pathogens isolated from the urine and catheter biofilm.

\subsection{Antibiotic Resistance Pattern of Urine Isolates}

Table 3 shows the antibiogram of the isolated pathogens against the antibiotic agents and their concentrations. An average of $80 \%$ of the isolates recovered in urine was resistant to ciprofloxacin while about $40.8 \%$ of the same isolates were resistant to nitrofurantoin representing the highest and lowest levels of resistance in urine isolates. High ciprofloxacin resistance was seen across all the urine isolates. The lowest resistances recorded for each urine pathogen showed; $E$. coli (32.8\%), K. pneumoniae (64.7\%) and $S$. aureus (28\%) all to nitrofurantoin. 


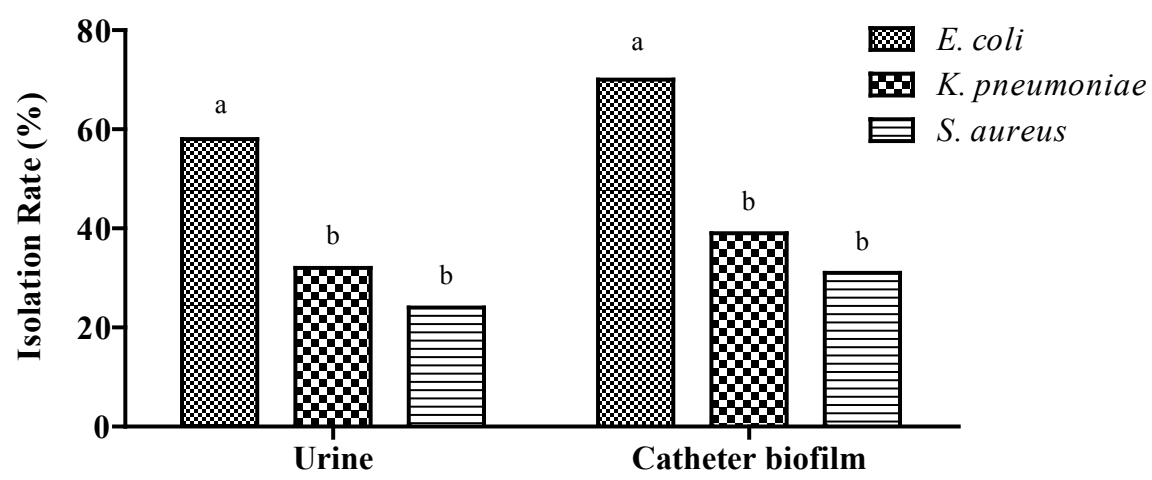

Figure 1. Isolation of uropathogens from urine and biofilm of catheterized patients. (Bars within a group with different alphabets indicate significant difference among the isolation rate of uropathogens).

Table 3. Antibiotic resistance of pathogens isolated from urine.

\begin{tabular}{cccccccc}
\hline Antibiotic & $\begin{array}{c}\text { Total } \\
(\mathrm{n}=120)\end{array}$ & $\begin{array}{c}\text { E. coli } \\
(\mathrm{n}=61)\end{array}$ & $\begin{array}{c}\text { K. pneumoniae } \\
(\mathrm{n}=34)\end{array}$ & $\begin{array}{c}\text { S. aureus } \\
(\mathrm{n}=25)\end{array}$ & P-value $^{\mathrm{a}}$ & P-value $^{\mathrm{b}}$ & P-value $^{\mathrm{c}}$ \\
\hline FOS 50 & $21(17.5 \%)$ & $21(34.4 \%)$ & $\mathrm{ND}$ & $\mathrm{ND}$ & $\mathrm{ND}$ & $\mathrm{ND}$ & $\mathrm{ND}$ \\
CIP 5 & $96(80 \%)$ & $53(86.9 \%)$ & $24(70.6 \%)$ & $19(76 \%)$ & 0.061 & 0.770 & 0.218 \\
KZ 30 & $75(62.5 \%)$ & $42(68.9 \%)$ & $24(70.6 \%)$ & $9(36 \%)$ & 1.000 & 0.016 & 0.007 \\
W 5 & $83(69.2 \%)$ & $43(70.5 \%)$ & $23(67.7 \%)$ & $17(68 \%)$ & 0.818 & 1.000 & 0.802 \\
F 300 & $49(40.8 \%)$ & $20(32.8 \%)$ & $22(64.7 \%)$ & $7(28 \%)$ & 0.004 & 0.008 & 0.799 \\
\hline
\end{tabular}

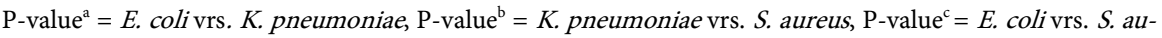
reus. FOS 50-Fosfomycin $(50 \mathrm{mcg})$, CIP 5 -Ciprofloxacin $(5 \mathrm{mcg}), \mathrm{KZ} 30$-Cefazolin $(30 \mathrm{mcg}), \mathrm{W}$ 5-Trimethoprim (5 mcg), F 300-Nitrofurantoin (300 mcg), ND—Not Determined.

Both $E$. coli and $K$. pneumoniae recorded higher resistance to cefazolin than $S$. aureus but were not statistically significant $(\mathrm{p}=1.000)$. However, the resistance between $S$. aureus and $E$. coli $(\mathrm{p}=0.007)$ and $S$. aureus and $K$. pneumoniae $(\mathrm{p}=$ $0.016)$ were significant. $K$. pneumoniae resistance to nitrofurantoin was significantly higher than $E$. coli $(\mathrm{p}=0.004)$ and $S$. aureus $(\mathrm{p}=0.008)$. However, E. coli and $S$. aureus resistance to nitrofurantoin was not significantly different $(\mathrm{p}=$ 0.799).

\subsection{Antibiotic Resistance Pattern of Biofilm Isolates}

Resistance observed for biofilm isolates was generally prevalent in trimethoprim (80.3\%) and ciprofloxacin (79.6\%). E. coli and S. aureus recorded $80.8 \%$ and $84.9 \%$ as the highest resistance rate to ciprofloxacin respectively whilst $K$. pneumoniae recorded $90.2 \%$ resistance to cefazolin (Table 4 ). E. coli recorded a $35.6 \%$ lower resistance rate for nitrofurantoin. $K$. pneumoniae resistance to fosfomycin was significantly higher $(\mathrm{p}=0.009)$ compared to $S$. aureus and $E$. coli but $S$. aureus resistance was higher than $E$. coli. Cefazolin resistance between $E$. coli and $K$. pneumoniae recorded significant resistance $(\mathrm{p}=0.003)$. However, the resistance between $S$. aureus and $E$. coli was not significant $(\mathrm{p}=0.283)$. 
Table 4. Antibiotic resistance of pathogens isolated from catheter biofilm.

\begin{tabular}{cccccccc}
\hline Antibiotic & $\begin{array}{c}\text { Total } \\
(\mathrm{n}=147)\end{array}$ & $\begin{array}{c}\text { E. coli } \\
(\mathrm{n}=73)\end{array}$ & $\begin{array}{c}\text { K. pneumoniae } \\
(\mathrm{n}=41)\end{array}$ & $\begin{array}{c}\text { S. aureus } \\
(\mathrm{n}=33)\end{array}$ & P-value $^{\mathrm{a}}$ & P-value $^{\mathrm{b}}$ & P-value $^{\mathrm{c}}$ \\
\hline FOS 50 & $36(24.5 \%)$ & $36(49.3 \%)$ & $\mathrm{ND}$ & $\mathrm{ND}$ & $\mathrm{ND}$ & $\mathrm{ND}$ & $\mathrm{ND}$ \\
CIP 5 & $117(79.6 \%)$ & $59(80.8 \%)$ & $30(73.2 \%)$ & $28(84.9 \%)$ & 0.355 & 0.266 & 0.786 \\
KZ 30 & $101(68.7 \%)$ & $47(64.4 \%)$ & $37(90.2 \%)$ & $17(51.5 \%)$ & 0.003 & 0.000 & 0.283 \\
W 5 & $118(80.3 \%)$ & $55(73.3 \%)$ & $35(85.4 \%)$ & $28(84.9 \%)$ & 0.239 & 1.000 & 0.318 \\
F 300 & $75(51.0 \%)$ & $26(35.6 \%)$ & $32(78.1 \%)$ & $17(51.5 \%)$ & 0.000 & 0.025 & 0.139 \\
\hline
\end{tabular}

$\mathrm{P}_{\text {-value }}{ }^{\mathrm{a}}=$ E. coli vrs. $K$. pneumoniae, $\mathrm{P}$-value ${ }^{\mathrm{b}}=K$. pneumoniae vrs. $S$. aureus, $\mathrm{P}$-value ${ }^{\mathrm{c}}=$ E. coli vrs. $S$. aureus. FOS 50-Fosfomycin (50 mcg), CIP 5-Ciprofloxacin (5 mcg), KZ 30-Cefazolin (30 mcg), W 5-Trimethoprim (5 mcg), F 300-Nitrofurantoin (300 mcg), ND-Not Determined.

Again, higher resistance was recorded for $K$. pneumoniae against nitrofurantoin compared to $S$. aureus and $E$. coli. Significant resistance $\mathrm{P}<0.000$ was recorded between $K$. pneumoniae and $E$. coli against nitrofurantoin likewise that of $S$. aureus and $K$. pneumoniae recorded p-value of 0.025 . Nevertheless, nitrofurantoin resistance to $S$. aureus and $E$. coli was not statistically significant (0.139).

Comparably, the biofilm isolates were more resistant to the tested drugs than the urine isolates. E. coli isolates from biofilm showed high resistance against fosfomycin than the urine isolates. For $K$. pneumoniae, the biofilm isolates resistance to cefazolin was higher compared to the urine isolates. In the catheter biofilm isolates also, resistance for $E$. coli ranged from $35.6 \%$ (nitrofurantoin) to $80.8 \%$ (ciprofloxacin). K. pneumoniae showed a range of $73.2 \%$ for ciprofloxacin to $90.2 \%$ for cefazolin. For $S$. aureus, the resistance ranged between $51.5 \%$ (nitofurantoin and cefazolin) and $84.9 \%$ (trimethoprim and ciprofloxacin). In effect, ciprofloxacin was mostly resistant across both urine and catheter biofilm isolates. Whiles $K$. pneumoniae showed a higher resistance pattern to the tested drugs than E. coli and $S$. aureus.

\section{Discussion}

\subsection{Demographic and Clinical Features of Study Participants}

In this study, most of the participants were males, this is comparable to a study at KATH, Kumasi which recorded only 8 females out of over two hundred urinary retention patients [17]. Another study also recorded 16/122 females from catheterized patients in Nigeria [18] whilst a lower sample size of nineteen elsewhere in Ghana recorded all (100\%) males [19]. The higher male records could be attributed to the problem of prostate enlargement being the most likely reason for urinary retention among men, leading to catheterization [14] [17]. The mean age for this study was $61.6 \pm 17.28$ similar to 62 recorded in the same facility [20] and $69.1 \%$ recorded at Korle-Bu Teaching Hospital [14] but contrary to $75.33 \pm 5.7$ recorded in Nigeria [13].

These attest to the fact that aging is a predisposal condition to prostate enlargement affecting normal urine flow in men [17]. 


\subsection{Isolated Pathogens in Urine and Biofilm}

In line with studies by Mujumder et al. in Bangladesh and Taiwo and Aderoun$\mathrm{mu}$, in Nigeria, there was a $100 \%$ and $97 \%$ growth of uropathogens from the catheter biofilm and urine samples respectively [18] [21]. Urine is supposed to be a sterile human sample but the invasion of the bladder with a catheter could be an evidential source of contamination. In both urine and biofilm samples, E. coli was the commonest pathogen isolated followed by $K$. pneumoniae and $S$. aureus. These isolated pathogens are usually associated with CAUTI [6] [7].

The pattern of isolation in this study is consistent with several other studies [15] [22] [23] but contrary to Taiwo and Aderounmu, and Ramadan et al. who reported $K$. pneumoniae as the most prevalent pathogen from catheterized patients [7] [18]. Most of these isolates are common pathogens in the hospital settings which may find their way into the urinary tract as a result of cross-contamination through health attendants, insertion of a catheter into the bladder, urine collection bag, breakage or leakage in the drainage system and the patient's own body or clothes [24].

Prevalence of CAUTI in this study was $74.29 \%$ which is in line with $74.6 \%$ in Nigeria [18], 73.3\% in Pakistan [22], 72.1\% in northern Ghana [15] and 76.6\% in Accra [14]. However, higher prevalence rate than this study was recorded among CAUTI patients in Nigeria [13] [18] but lower rates (17.5\%) and (43.5\%) than this study were recorded in Egypt and India respectively [7] [25]. The high prevalence recorded in this study could be linked to the long period of catheterization. The study revealed that more than $95 \%$ of the patients were catheterized for more than one month and about $65 \%$ were catheterized for more than one year. Having in mind that there is about $10 \%$ daily infection rate as catheter is in situ [11]. Again, more than $83 \%$ of the participants aged above 50 years could be a predisposal factor to CAUTI. Males are prone to obstructive urinary conditions like Benign Prostate Hyperplasia (BPH) and prostate enlargement with advance ageing coupled with weak immunity [13].

Moreover, the biofilms formed around the catheter can find their way into the bladder to cause infection. Such infections are rarely symptomatic, about $66.67 \%$ of CAUTI cases for this study were asymptomatic which agrees with a study elsewhere [23]. Studies by Majumder et al. and Tambyah and Maki showed more than $90 \%$ of CAUTI patients were asymptomatic. The asymptomatic nature of most catheterized patients is due to the presence of catheter in the urethra which protects its mucosa from microbial invasion resulting in inflammation which usually presents characteristic signs and symptoms of UTI such as dysuria and urgency [21] [26].

\subsection{Antibiotic Resistance of Urine and Biofilm Isolates}

Averagely $77 \%$ of the uropathogens isolated from the urine were resistant to ciprofloxacin. The pathogen distribution to ciprofloxacin resistance shows $86.89 \%$, $76 \%$ and $70.6 \%$ for E. coli, S. aureus and K. pneumoniae respectively. This con- 
firms a study by Milan which shows higher ciprofloxacin resistance among catheterized patients [27]. Similar resistant trend in catheterized Bladder Outlet Obstruction (BOO) patients recording $92.3 \%$ and $74.2 \%$ for $E$. coli and $K$. pneumoniae to ciprofloxacin [14] but contrary to a recorded $100 \%$ resistance for isolated uropathogen [28]. The resistance to ciprofloxacin could be attributed to the fact that ciprofloxacin is the commonest antibiotic used by the most catheterized patients in Ghana [6] [29]. Cefazolin and nitrofurantoin resistance to Klebsiella were significantly higher compared to either $S$. aureus or E. coli. However, that of $E$. coli and $S$. aureus was not significantly different for nitrofurantoin but resistance between Klebsiella and $E$. coli was significantly different whiles that of $E$. coli and $S$. aureus was not $(\mathrm{P}=0.799)$.

Regarding resistance to the biofilm isolates, this study is true for other studies that showed higher resistance among the biofilm isolates than the non-biofilm isolates [7] [21] [30]. High resistance to Ciprofloxacin was observed in similar studies which agree with this study revealing trimethoprim and ciprofloxacin as higher resistance to biofilm pathogens [21]. Nitrofurantoin had lower resistance rates and can be considered for CAUTI treatment contrary to similar studies elsewhere [7] [31]. Generally, in concordant with Qayoom, K. pneumoniae isolated from biofilm exhibited higher resistance levels than the other isolates [32] and these could be attributed to $K$. pneumoniae's high potential to producing biofilm [7].

\section{Conclusion}

The study reveals that most men are catheterized due to urinary retention caused by prostate enlargement problems. Hypertension was considered a common comorbidity among catheterized patients. Contamination during catheterization period resulted in biofilm formation and high CAUTI incidences that were rarely symptomatic. E. coli was significantly isolated from both urine and biofilm samples. However, more pathogens were recorded from the catheter biofilm than in the urine sample. The study also outlined a high resistance pattern among the biofilm isolates compared to the planktonic isolates from the urine. Considering the level of resistance exhibited by the isolates, this study can conclude that $K$. pneumoniae was mostly resistance to the antibiotics than $E$. coli and $S$. aureus. In addition, ciprofloxacin, mostly used by CAUTI patients is less effective for pathogens isolated for this study. CAUTI treatment should therefore be based on pathogens susceptibility to antibiotics.

\section{Acknowledgements}

We thank the staff of urology department of KATH and all patients who participated in this study.

\section{Conflicts of Interest}

The authors declare no conflict of interest. 


\section{References}

[1] Hooton, T.M., Bradley, S.F., Cardenas, D.D., Colgan, R., Geerlings, S.E., Rice, J.C., Nicolle, L.E., et al. (2010) Diagnosis, Prevention, and Treatment of Catheter-Associated Urinary Tract Infection in Adults: 2009 International Clinical Practice Guidelines from the Infectious Diseases Society of America. Clinical Infectious Diseases, 50, 625-663. https://doi.org/10.1086/650482

[2] Jacobsen, S.M., Stickler, D.J., Mobley, H.L.T. and Shirtliff, M.E. (2008) Complicated Catheter-Associated Urinary Tract Infections Due to Escherichia coli and Proteus mirabilis. Clinical Microbiology Reviews, 21, 26-59. https://doi.org/10.1128/CMR.00019-07

[3] Nicolle, L.E. (2014) Catheter Associated Urinary Tract Infections. Antimicrobial Resistance and Infection Control, 3, Article No. 23. https://doi.org/10.1186/2047-2994-3-23

[4] Percival, S.L., Suleman, L., Vuotto, C. and Donelli, G. (2015) Healthcare-Associated Infections, Medical Devices and Biofilms: Risk, Tolerance and Control. Journal of Medical Microbiology, 64, 323-334. https://doi.org/10.1099/jmm.0.000032

[5] Albu, S., Voidazan, S., Bilca, D., Badiu, M., Truță, A., Ciorea, M., Moldovan, G., et al. (2018) Bacteriuria and Asymptomatic Infection in Chronic Patients with Indwelling Urinary Catheter: The Incidence of ESBL Bacteria. Medicine, 97, e11796. https://doi.org/10.1097/MD.0000000000011796

[6] Bekoe, A., Azorliade, R., Ablordey, A. and Addo, M.G. (2020) Antibiotic Resistance and Genotypic Detection of Extended Spectrum Beta-Lactamase Producing Pathogens in Catheter Associated Urinary Tract Infection at a Teaching Facility in Kumasi, Ghana. African Journal of Microbiology Research, 14, 395-401. https://doi.org/10.5897/AJMR2020.9374

[7] Ramadan, R., Omar, N., Dawaba, M. and Moemen, D. (2021) Bacterial Biofilm Dependent Catheter Associated Urinary Tract Infections: Characterization, Antibiotic Resistance Pattern and Risk Factors. Egyptian Journal of Basic and Applied Sciences, 8 , 64-74. https://doi.org/10.1080/2314808X.2021.1905464

[8] Dufour, D., Leung, V. and Lévesque, C.M. (2010) Bacterial Biofilm: Structure, Function, and Antimicrobial Resistance. Endodontic Topics, 22, 2-16. https://doi.org/10.1111/j.1601-1546.2012.00277.x

[9] Murugan, K., Selvanayaki, K. and Al-Sohaibani, S. (2016) Urinary Catheter Indwelling Clinical Pathogen Biofilm Formation, Exopolysaccharide Characterization and Their Growth Influencing Parameters. Saudi Journal of Biological Sciences, 23, 150-159. https://doi.org/10.1016/j.sjbs.2015.04.016

[10] World Health Organization (2011) Report on the Burden of Endemic Health Care-Associated Infection Worldwide.

[11] Amalaradjou, M.A.R. and Venkitanarayanan, K. (2013) Role of Bacterial Biofilms in Catheter-Associated Urinary Tract Infections (CAUTI) and Strategies for Their Control. Recent Advances in the Field of Urinary Tract Infections, 10, 1-32. https://doi.org/10.5772/55200

[12] Dougnon, T.V., Bankole, H.S., Johnson, R.C., Hounmanou, G., Moussa Toure, I., Houessou, C., Baba-Moussa, L., et al. (2016) Catheter-Associated Urinary Tract Infections at a Hospital in Zinvie, Benin (West Africa). International Journal of Infection, 3, e34141. https://doi.org/10.17795/iji-34141

[13] Adegun, P.T., Odimayo, M.S., Olaogun, J.G. and Emmanuel, E.E. (2019) Comparison of Uropathogens and Antibiotic Susceptibility Patterns in Catheterized Ambulant Middle-Aged and Elderly Nigerian Patients with Bladder Outlet Obstruction. 
Turkish Journal of Urology, 45, 48-55. https://doi.org/10.5152/tud.2018.25588

[14] Asafo-Adjei, K., Mensah, J.E., Labi, A.K., Dayie, N.T. and Donkor, E.S. (2018) Urinary Tract Infections among Bladder Outlet Obstruction Patients in Accra, Ghana: Aetiology, Antibiotic Resistance, and Risk Factors. Diseases, 6, 65. https://doi.org/10.3390/diseases6030065

[15] Yenli, E.M.T.A., Ankrah, J.N.O., Zeyeh, D.E. and Ziem, J.B. (2019) Catheter-Associated Bacteria Urinary Tract Infection and Antibiotic Susceptibility Pattern in a Tertiary Hospital, in Ghana. Open Journal of Urology, 9, 140-151. https://doi.org/10.4236/oju.2019.99017

[16] Clinical and Laboratory Standards Institute (2018) CLSI. M100 Performance Standards for Antimicrobial Susceptibility Testing. 28th Edition, CLSI, Wayne, PA.

[17] Yenli, E.M.T., Aboaha, K., Gyasi-Sarponga, C.K., Azorliade, R. and Arhina, A.A. (2015) Acute and Chronic Urine Retention among Adults at the Urology Section of the Accident and Emergency Unit of Komfo Anokye Teaching Hospital, Kumasi, Ghana. African Journal of Urology, 21, 129-136.

https://doi.org/10.1016/j.afju.2014.08.009

[18] Taiwo, S.S. and Aderounmu, A.O.A. (2006) Catheter Associated Urinary Tract Infection: Aetiologic Agents and Antimicrobial Susceptibility Pattern in Ladoke Akintola University Teaching Hospital, Osogbo, Nigeria. African Journal of Biomedical Research, 9, 141-148. https://doi.org/10.4314/ajbr.v9i3.48897

[19] Atakro, C., Boni, G. and Gross, J. (2017) Socio-Economic Impact of Indwelling Urethral Catheter: The Experiences of Patients Discharged from the Volta Regional Hospital of Ghana. NUMID Horizon, 1, 41-48.

[20] Gyasi-Sarpong, C.K., Nkrumah, B., Yenli, E.M.T.A., Appiah, A.A., Aboah, K., Azorliade, R., Ali, I., et al. (2014) Resistance Pattern of Uropathogenic Bacteria in Males with Lower Urinary Tract Obstruction in Kumasi, Ghana. African Journal of Microbiology Research, 8, 3324-3329. https://doi.org/10.5897/AJMR2014.6894

[21] Majumder, M.I., Ahmed, T., Hossain, D., Ali, M., Islam, B. and Chowdhury, N.H. (2014) Bacteriology and Antibiotic Sensitivity Patterns of Urine and Biofilm in Patients with Indwelling Urinary Catheter in a Tertiary Hospital in Bangladesh. Journal of Bacteriology and Parasitology, 5, Article ID: 1000191.

https://doi.org/10.4172/2155-9597.1000191

[22] Sabir, N., Ikram, A., Zaman, G., Satti, L., Gardezi, A., Ahmed, A. and Ahmed, P. (2017) Bacterial Biofilm-Based Catheter-Associated Urinary Tract Infections: Causative Pathogens and Antibiotic Resistance. American Journal of Infection Control, 45, 1101-1105. https://doi.org/10.1016/j.ajic.2017.05.009

[23] Onyegbule, O.A., Udigwe, G.O., Ezebialu, I., Nduka, A.C., Okolie, V.E. and Okor, O.L. (2014) Catheter-Associated Urinary Tract Infection Following Caesarean Section in Nnewi, Nigeria: A Prospective Comparative Study. British Microbiology Research Journal, 4, 1025-1034. https://doi.org/10.9734/BMRJ/2014/10097

[24] George, D.F., Gbedema, S.Y., Agyare, C., Adu, F., Boamah, V.E., Tawiah, A.A. and Saana, S.B.B.M. (2012) Antibiotic Resistance Patterns of Escherichia Coli Isolates from Hospitals in Kumasi, Ghana. International Scholarly Research Notices, 2012, Article ID: 658470. https://doi.org/10.5402/2012/658470

[25] Bhani, D., Bachhiwal, R., Sharma, R. and Maheshwari, R.K. (2017) Microbial Profile and Antimicrobial Susceptibility Pattern of Uropathogens Isolated From Catheter Associated Urinary Tract Infection (CAUTI). International Journal of Current Microbiology and Applied Sciences, 6, 2446-2453.

https://doi.org/10.20546/ijcmas.2017.608.289 
[26] Tambyah, P.A. and Maki, D.G. (2000) Catheter-Associated Urinary Tract Infection Is Rarely Symptomatic: A Prospective Study of 1497 Catheterized Patients. Archives of Internal Medicine, 160, 678-682. https://doi.org/10.1001/archinte.160.5.678

[27] Milan, P.B. and Ivan, I.M. (2009) Catheter-Associated and Nosocomial Urinary Tract Infections: Antibiotic Resistance and Influence on Commonly Used Antimicrobial Therapy. International Urology and Nephrology, 41, Article No. 461. https://doi.org/10.1007/s11255-008-9468-y

[28] Alam, J., Juliana, F.M., Rahimgir, M., Hossain, M.N., Fatema, B. and Asaduzzaman, M. (2017) Resistance Pattern of Ciprofloxacin against Common Uropathogens in Selected Area of Dhaka City, Bangladesh. IOSR Journal of Nursing and Health Science (IOSR-JHNS), 6, 52-57.

[29] Gyansa-Lutterodt, M., Afriyie, D.K., Asare, G., Amponsah, S., Abutiate, H. and Darko, D. (2014) Antimicrobial Use and Susceptibility Pattern of Uropathogens Associated with Urinary Tract Infections at the Ghana Police Hospital. Global Journal of Pharmacology, 8, 306-315.

[30] Deotale, V.S., Attal, R., Joshi, S. and Bankar, N. (2015) Correlation between Biofilm Formation and Highly Drug Resistant Uropathogens (HDRU). International Journal of Current Research and Review, 7, 61-65.

[31] Abdallah, N.M.A., Elsayed, S.B., Mostafa, M.M.Y. and El-Gohary, G.M. (2011) Biofilm Forming Bacteria Isolated from Urinary Tract Infection, Relation to Catheterization and Susceptibility to Antibiotics. International Journal of Biotechnology and Molecular Biology Research, 2, 172-178.

[32] Qayoom, J., Haswani, N. and Pai, V. (2018) Study of Biofilm Formation and Its Correlation with Highly Drug Resistant Uropathogens in Catheter-Associated Urinary Tract Infection. Journal of International Medicine and Dentistry, 5, 87-92. https://doi.org/10.18320/JIMD/201805.0287 